\section{EMBRYARIDDLE \\ Aeronautical University}

SCHOLARLY COMMONS
International Journal of Aviation, Aeronautics, and Aerospace

\title{
Design and Realization of an Unmanned Aerial Rotorcraft Vehicle Using Pressurized Inflatable Structure
}

\author{
Nirmal Sadasivan \\ NSS COLLEGE OF ENGINEERING, PALAKKAD, nirmalsadasivan@gmail.com
}

Follow this and additional works at: https://commons.erau.edu/ijaaa

Part of the Aerodynamics and Fluid Mechanics Commons, Aeronautical Vehicles Commons, MultiVehicle Systems and Air Traffic Control Commons, Other Aerospace Engineering Commons, and the Systems Engineering and Multidisciplinary Design Optimization Commons

\section{Scholarly Commons Citation}

Sadasivan, N. (2019). Design and Realization of an Unmanned Aerial Rotorcraft Vehicle Using Pressurized Inflatable Structure. International Journal of Aviation, Aeronautics, and Aerospace, 6(4). https://doi.org/ 10.15394/ijaaa.2019.1352

This Article is brought to you for free and open access by the Journals at Scholarly Commons. It has been accepted for inclusion in International Journal of Aviation, Aeronautics, and Aerospace by an authorized administrator of Scholarly Commons. For more information, please contact commons@erau.edu. 


\section{Introduction}

An unmanned aerial vehicle (UAV), commonly known as a drone, is an aircraft that can navigate without a human pilot onboard. A ballistic or semiballistic vehicle, cruise missiles, artillery projectiles, torpedoes, mines, and satellites are not considered as an unmanned aerial vehicle (UK MoD, 2011). Depending on the platform and the mission, a broad range of UAV configurations exists (Hassanalian, \& Abdelkefi, 2017). Basic classification of UAVs are Fixed wing, Flapping wing, and Rotary wing (Ghazbi, Aghli, Alimohammadi, \& Akbari, 2016). Each type has advantages and exhibits inherent limitations. Based on the number and layout of the motors, there are different configurations for rotary wing drones like twin copters, tricopters, quadcopters, pentacopters, hexacopters, octocopters, decacopters, and dodecacopters. Among them, the quad-copters and hexacopters are the bestknown drones (Hassanalian, \& Abdelkefi, 2017). Another general categorisation is horizontal take off landing (HTOL) and vertical take-off landing (VTOL) vehicles. The quadrotor has good ranking among VTOL vehicles because of strong flexibility, high energy utilization rate, well-designed structure and high security (Papa, Pointe, \& Core, 2017; Wang, Le, \& Fan, (2013). According to Stratistics MRC (2016), the global UAV drone's market is estimated at $\$ 5.93$ billion in 2015 and is expected to reach $\$ 22.15$ billion by 2022 growing at a CAGR of $20.7 \%$ from 2015 to 2022. A new forecast study by Markets and Markets (2018) estimates the UAV market that was valued at USD 18.14 Billion in 2017 is to reach USD 52.30 Billion by 2025, at a CAGR of $14.15 \%$ from 2018 to 2025 .

The applications of drones can be categorized based on the type of missions (military/civil), type of the flight zones (outdoor/indoor), and type of the environments (underwater/on the water/ground/air/space) (Hassanalian \& Abdelkefi, 2017). The application includes monitoring and surveillance of areas urban traffic (Salvo, Caruso, \& Scordo, 2014), coast guard and border patrolling (Kim \& Lim, 2018), earth resource monitoring (Berie \& Burud, 2018; Murfitt et al., 2017), mapping (Hackney \& Clayton, 2015; Jurić-Kaćunić, Librić, \& Car, 2016), climate research, such as air composition pollution studies (Villa, Gonzalez, Miljievic, Ristovski, \& Morawska, 2016), and environmental protection (Duan \& Zhang, 2014), agricultural studies (Psirofonia, Eliopoulos, Samaritakis, \& Potamitis, 2017; Puri, Nayyar, \& Raja, 2017; Reinecke \& Prinsloo, 2017), inspection of electrical power lines (Zhou, Yuan, Yen, \& Bastani, 2016), monitoring gas or oil pipelines Ondráček, Vaněk, \& Pěchouček, 2014), entertainment (Kim, Jeong, Park, Ryu, \& Oh, 2017; Ohta, 2017), search and rescue missions (Choi, Cheon, Kim, \& Lee, 2016), mailing and delivery (Lisso, 2017), performing missions in oceans or other planets (Hassanalian, Rice, \& Abdelkefi, 2018), and other miscellaneous applications.

One of the key parameters for designing a rotary wing vehicle for these applications is to know the requirements of the mission. Flight requirements mainly include endurance duration, payload capacity, the range of flight, speed 
and flight altitude. For rotorcraft vehicles, weight is an important parameter (Hassanalian \& Abdelkefi, 2017). They are advantageous since they do not require any runways or launching equipment for take-off and landing. While executing a mission, the unique hovering capability of rotorcraft vehicles brings much-enhanced flexibility. However wide-range coverage or long endurance missions are not feasible due to its low-speed and endurance limit (Cetinsoy, 2012; Saeed, Younes, Cai, \& Cai, 2018). The current UAV's flight time is limited because of heavy lift-power needed to take off and maintaining the flight in the air (Hassanalian \& Abdelkefi, 2017; Papa et al., 2017). The exposed rotor blades of multirotor vehicles are very dangerous for the animals, birds, as well as for the humans, while perfectly working and under any circumstances of system failure (Edge, Brown, \& Collins, 2012). The existing mainstream UAVs are not capable of stealth and are easily spotted and/or heard (Sepulveda \& Smith, 2017). These deficiencies cause a significant drop in the potential of unmanned aerial rotorcraft vehicles for various applications. There is a necessity to advance the performance on several ranges of UAV performance for the successful use of these vehicles in expanded future roles. This work presents the design and realization of a rotorcraft using pressurized structure filled with lighter than air gas such as hydrogen or helium to provide lift assistance for the vehicle and thus improve its performance.

\section{Related Works}

The pressurized structure is a generalized term that describes an inflatable UAV component. In 2012, Edge et al.'s research report mentions that different types of UAV designs will require different types of pressurized structure solutions. The most common concepts for UAVs employing inflatable structures are blimps and aerostats. An aerostat is a lighter than air aircraft that achieves its lift through the use of a lighter than air gas. Aerostats include unpowered balloons and powered airships. There are several works that are done on the design of blimps (Boon, 2004; Gawale, 2002; Hollinger, Pezzementi, Flurie, \& Maxwell, 2005; Nordestgaard, Ravenscroft, \& Bartel, 2007) and aerostat (Callwood, 2014; Kumar, Sati, \& Ghosh, 2016; Miller, 2005; Van Dosselaer, 2014). Airships typically have a high length to diameter ratio envelope to decrease the drag. Another concept that is getting popularized is to replace the conventional standard wing with a pressurized inflatable wing. The work (Simpson et al., 2004; Smith, Uhelsky, \& Mackusick, 2004) concluded that inflatable wings are feasible and offers other benefits, including the ability to stuff the wings in a small space until required, improved aerodynamic characteristics over similar profiles at low speeds, and the ability to warp. The morphing inflatable wing will be an attractive option for various UAV applications. A new idea for the low-altitude and low-speed aircraft was proposed in which uses an airbag to cope with the difficulties in the field of Airborne Geophysical Prospecting (Wang et al. 2013). Another research work (Papa et al., 2017) discussed the main phases of the conceptual design of a lowcost electrically powered hybrid UAS for extending cruise endurance by using 
a lighter than air gas filled balloon. A group of researchers developed and experimented (Sharf, Persson, St.-Onge, \& Reeves, 2013) with a spherical blimp developed at McGill and a cubical blimp developed at UQAM. The spherical blimp represents a novel concept for satellite emulation in the laboratory and the cubical blimp was developed for use in floating architecture and visual art.

Bionic Learning Network, a research network set up by Festo AG, have come up with many projects that mimic the motion from nature. Many of their projects utilize the concept of pressurized structure technology to realize the idea. AirJelly, AirPenguin, AirRay and FreeMotionHandling are some of their projects. AirJelly (Festo, n.d.a). is a remote radio-controlled airborne jellyfish with a helium-filled ballonet of diameter 1.35 meters, a central electric drive unit, and an intelligent adaptive mechanism. The project had its inspiration for adapting the propulsion mechanisms of marine creatures in the aviation sector. The AirPenguin (Festo, n.d.b) is an autonomously flying object and is a natural archetype of a penguin comprising a helium-filled ballonet generating approximately $1 \mathrm{~kg}$ of buoyant force. Air-ray (Festo, n.d.c) is a radio-controlled airborne hybrid comprising a helium-filled ballonet and a flapping-wing drive mechanism. FreeMOtionHandling (Festo, n.d.d) is an indoor flying object with an integrated gripping element. It consists of a helium ball at centre and an ultralight carbon ring with eight adaptive propellers around the ball. The outside diameter of the balloon is $180 \mathrm{~cm}$ and has a max flight time of 40 minutes without payload.

Other interesting recent developments are the BalloonCam (Matsumoto, Ichimura, Itobe, \& Takita, 2014), Halo (Juang, 2017), Plimp (Atherton, 2017), and Skye (Burri et al., 2013). BalloonCam is a prototype created by Panasonic Corporation which combines a drone with a large balloon. Powered by four propellers, it can fly around and perform planned operations during events. Since the drone is completely wrapped in the large balloon, it can fly close and interact with the audience. Halo is a balloon drone hybrid from start-up Spacial. It has a lighter-than-air gas-filled envelope, four propellers and servos to move the drone to the point of interest. Plimp is a plane-blimp hybrid created by Egan Airships. Skye is a novel blimp design having a helium-filled sphere of diameter $2.7 \mathrm{~m}$ and four tetrahedral-arranged actuation units for locomotion.

\section{Design}

The basic components of the vehicle include a hull, structural frame, propulsion, and control system. The hull, which is a pressurized inflatable structure filled with lighter than air gas such as hydrogen or helium provide most of the aerostatic lift power for the vehicle. The hull can be of any shape. However, a spherical hull is considered for the vehicle due to its uniform symmetry, manufacturing easiness and low surface area to volume ratio. Power consumption of propulsion system can thus be reduced greatly and the UAV can have longer flight endurance. The vectored lift is provided by the lighter propellers and it helps to direct the vehicle to the point of interest. Aerodynamic 
lift is produced due to the shape of the hull and is negligible for a spherical hull. Static lift, aerodynamic lift, vectored lift, and gravity are the main forces that act on the system. The aerostatic lift is equal to the difference between the buoyant force and the weight of the displacing gas.

$$
\text { Lifting force }\left(L_{f}\right)=V\left(\rho_{\text {air }}-\rho_{\text {gas }}\right)
$$

where $\mathrm{V}$ is the volume of the envelope and $\rho$ is the density. There are essentially four modes for a UAV; take-off mode, hover mode, cruise mode, and landing mode. The take-off manoeuvre describes how the airship moves from the ground to its cruise altitude. In take-off mode, the airship must overcome the drag force acting downward as well as the weight force. The buoyancy force alone is not sufficient for take-off; hence, an upward thrust must be provided. The required thrust in take-off was determined from applying Newton's Second Law to the airship (Figure 1).

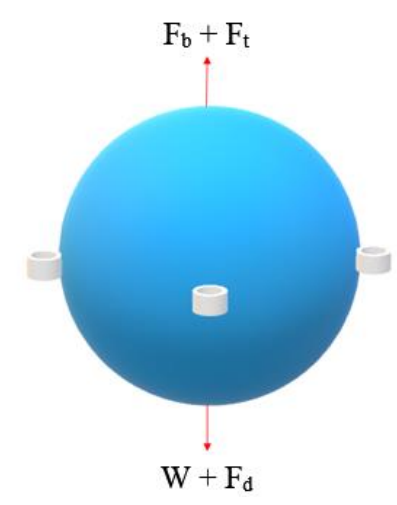

Figure 1. Free body diagram of take-off.

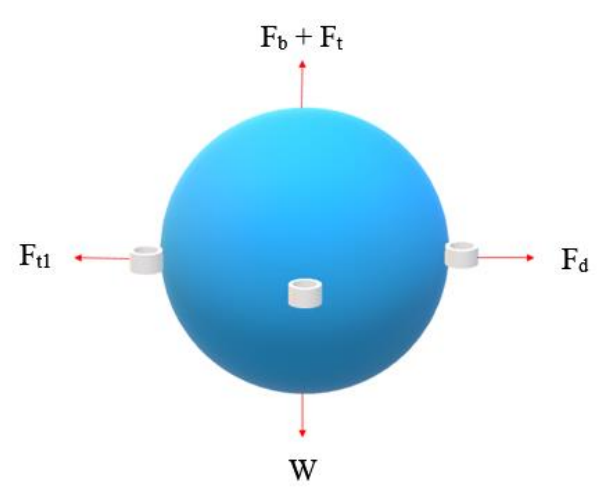

Figure 2. Free body diagram of cruising.

$$
\begin{aligned}
& \mathrm{F}=\mathrm{m}(\mathrm{dv} / \mathrm{dt})=\operatorname{Thrust}\left(\mathrm{F}_{\mathrm{t}}\right)+\operatorname{Buoyancy}\left(\mathrm{F}_{\mathrm{b}}\right)-\operatorname{Weight}(\mathrm{W})-\operatorname{Drag}\left(\mathrm{F}_{\mathrm{d}}\right) \\
& \text { where } \operatorname{Drag}\left(F_{d}\right)=0.5 C_{D} \rho_{\text {air }} A v^{2}
\end{aligned}
$$

$C_{D}$ is a dimensionless drag coefficient that is shape dependent, $\rho_{\text {air }}$ is the fluid density of air, $\mathrm{A}$ is the cross-sectional area, and $\mathrm{v}$ is the velocity of the vehicle. First, the assumptions (Gawale, 2002) have to be made viz. flow over the hull is turbulent and the drag has been estimated in terms of drag coefficient. Viscosity was calculated using:

$$
\mu=1.7140 * 10^{-5}\left(\frac{T s+\Delta T}{273}\right)^{4.256}
$$

where $\mathrm{Ts}$ is the standard atmospheric temperature, $\Delta \mathrm{T}$ is the temperature above standard atmospheric temperature and Reynold's number was estimated using (5). 


$$
\operatorname{Re}=\rho \operatorname{VD} / \mu
$$

To hover, a constant upward thrust is required to maintain altitude. The cruise mode is essentially the same as the hover mode except that it includes movement in the horizontal plane. In cruise mode, the airship requires thrust in both vertical and horizontal directions. The vertical thrust is equal to that needed for hover. The forward thrust was calculated by applying Newton's Second Law in the horizontal direction (Figure 2).

$$
\mathrm{F}=\mathrm{m}(\mathrm{dv} / \mathrm{dt})=\operatorname{Thrust}(\mathrm{Ft} 1)-\operatorname{Drag}(\mathrm{Fd})
$$

\section{Iterative Design}

Two iterative design procedures were developed for designing the vehicle. One was based on the net weight of the vehicle and the other based on the diameter of the spherical hull. Both designs utilize the motor-propeller configuration of multirotor.

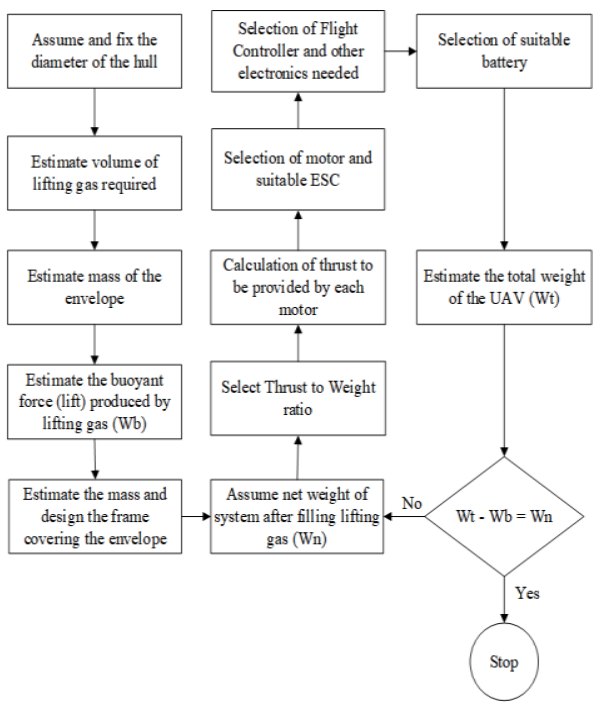

Figure 3. Design procedure 1.

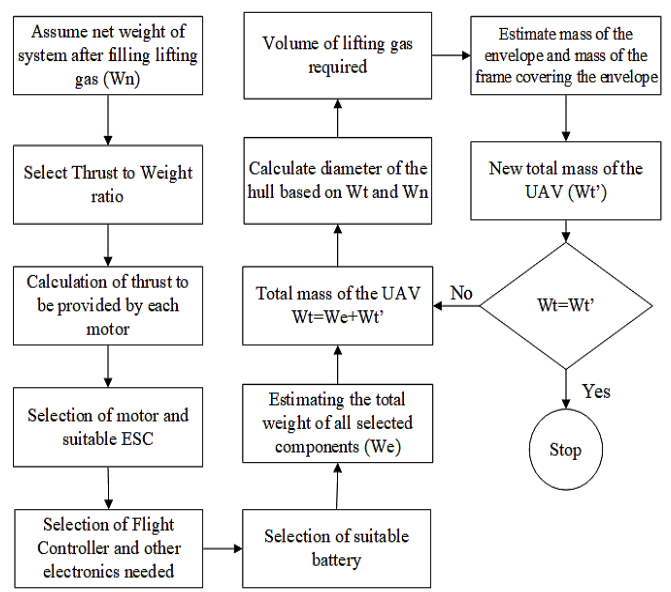

Figure 4. Design procedure 2.

\section{Design procedure 1.}

In this design procedure (Figure 3), the net weight of the system after filling lifting gas was first assumed and fixed. The diameter of the envelope varies depending on the total weight of all the components. The procedure could be used to design neutrally buoyant vehicles and also is mainly employed to design UAV in which its net weight is constrained.

\section{Design procedure 2.}

In this design procedure (Figure 4), the diameter of the hull is first assumed and fixed. Here, unlike the design procedure 1, the net weight of the system and weight of the components are iterated. The procedure could also be 
used to design neutrally buoyant vehicles. However, it is not very feasible to create small diameter neutrally buoyant vehicles because buoyancy lift obtained with a small volume of lifting gas is very low. The procedure is mainly employed to design a UAV in which it's the diameter of the hull is constrained.

\section{Lifting Gas}

Presently, the common gases used in aerostatics are hot air and helium (Callwood, 2014). Despite the cost, helium is the most efficient source of static lift for the airship because it is safe to use as it is an inert gas. Helium gas does not come in pure form. To account for the impurity, the density is with the following formula

$$
\rho=(k * 0.169+(1-k) * 1.225)
$$

where $\mathrm{k}$ is the percentage purity of helium. The density of helium is approximated to $0.169 \mathrm{~kg} / \mathrm{m}^{3}$ (Boon, 2004). There are instances when helium/hydrogen mix (Hollinger et al, 2005) were used in the airships that would allow for more lift given the same volume of gas. Other lighter than air gases include methane, ammonia, and hot air. Temperature and altitude have an effect on the density of lifting gas and thus the net lifting force produced. Air was assumed to be an ideal gas and hence the effect of temperature on the air density can be calculated by

$$
\rho=\frac{P * M}{R * T}
$$

where $\mathrm{P}=101325 \mathrm{~Pa}$ (atmospheric pressure in $\mathrm{Pa}$ ), $\mathrm{M}$ is molar mass of gas in $\mathrm{kg} / \mathrm{mol}$ (Table 1 ), and $\mathrm{R}$ is $8314 \mathrm{~J} / \mathrm{molK}$. The lifting force was then determined at varying temperatures by substitution of the density change into the lift equation (1) and plotting against temperature on the horizontal axis (Figure5).

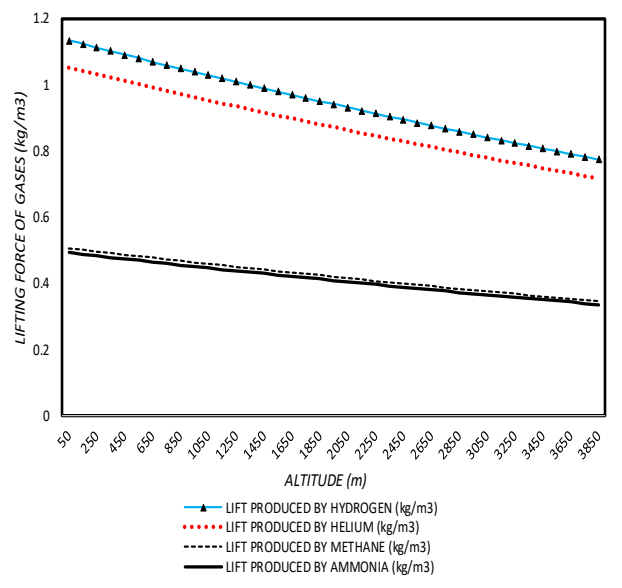

Figure 5. Variation of lift force for different gases with change in temperature.

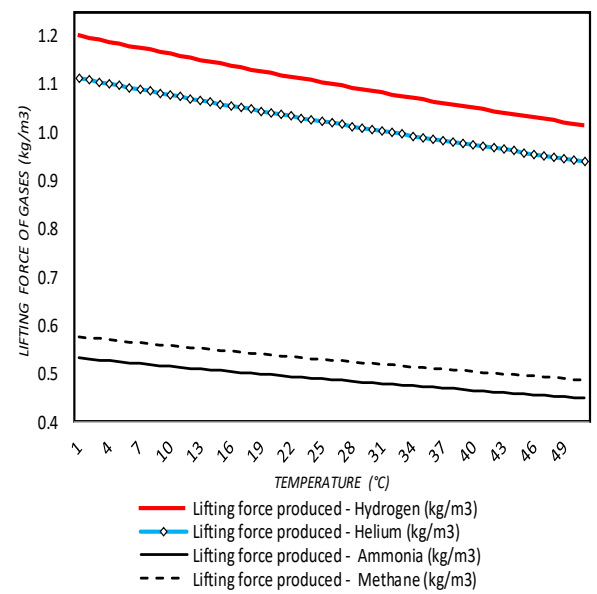

Figure 6. Variation of lift force for different gases with change in altitude. 
Table 1

Molar mass and density of gases at standard conditions.

\begin{tabular}{lll}
\hline Gas & Molar mass $(\mathrm{g} / \mathrm{mol})$ & Density $(\mathrm{kg} / \mathrm{m} 3)$ \\
\hline Air & 28.9647 & 1.225 \\
Hydrogen & 2.02 & 0.085 \\
Helium & 4.0026 & 0.169 \\
Ammonia & 17.031 & 0.756 \\
Methane & 6.04 & 0.73 \\
\hline
\end{tabular}

The relationship between temperature and altitude within $11000 \mathrm{~m}$ is given by the formula,

$$
T s=288.15-0.0065 H
$$

where $\mathrm{H}$ is the altitude from mean sea level. And the relationship between density of lifting gas and altitude is given by the formula,

$$
\rho_{s}=1.225\left(\frac{288.15-0.0065 H_{p}}{288.15}\right)^{4.2558797}
$$

where $\mathrm{Hp}$ is the pressure altitude. Different formulas are used to calculate the atmospheric details for different altitude range (Khoury \& Gillett, 2004). An altitude above $11000 \mathrm{~m}$ is called off-standard conditions and follows a different relationship. The variation of lifting force with a change in altitude is shown in Figure 6.

\section{Envelope Design}

\section{The diameter of the envelope hull.}

The diameter of the spherical hull is derived using the Archimedes principle. The lift equation given below is used to find the diameter. Figure 7 shows the relation between the diameter of the inflatable spherical balloon hull and lifting forces produced by different gases. As the diameter increases, there is a cubical increase in the lifting force.

$$
\text { Lifting force }\left(L_{f}\right)=\frac{4 \pi r^{3}\left(\rho_{\text {air }}-\rho_{\text {gas }}\right)}{3}
$$




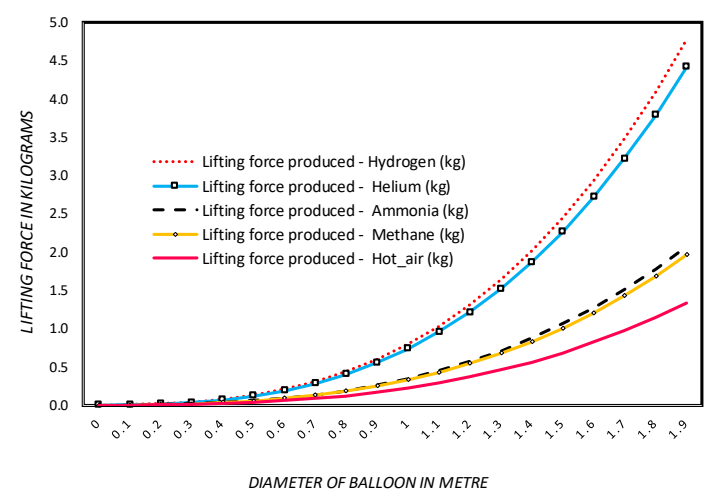

Figure 7. Gross static lift versus balloon diameter for different lifting gas.

\section{Inflatable envelope structure and its material.}

There are three main types of inflatable envelopes structure: rigid, semirigid and non-rigid (Callwood, 2014) The hull profile of non-rigid inflatable envelope is maintained by the pressure of the lifting gas within and no rigid structure is attached to distribute the payload on the envelope. The overall performance of the vehicle is influenced by the shape of the inflatable structure. Envelope weight and air resistance are proportional to surface area and in an ideal case, the surface area to volume ratio should be as small as possible. Hence, a spherical shape provides optimum lift efficiency (Khoury \& Gillett, 2004). Buoyancy versus drag is an important trade-off in designing lighter-thanair vehicles (Edge et al., 2012). The volume of lifting gas should be increased to increase the buoyancy. But as the volume increases the drag also increases due to the increase in the cross-sectional area.

The inflatable structure is most commonly made from two-dimensional pieces, or gores, that are assembled to make the 3-dimensional structures. The technique of development of sphere is used to create the spherical inflatable structure of the vehicle. For the smaller structures, cylindrical single-piece gores are used to reduce the number of seams. Gore numbers that are multiples of six are preferred and used in the industry (Miller, 2005). Increasing the number of cylindrical gores makes the structure less polygonal and more spherical. Figure 8 shows the construction of polyconic gores and Figure 9 depicts the procedure for construction of cylindrical gores (French, 1911). Joining is done by heatsealing or glueing in order to obtain a better load distribution throughout the seam and better resistance to shear, heat, and environmental degradation. For smaller inflatable structures, a simpler edge-to-edge heat-sealing process is used as there are only lower stresses at the seams (Miller, 2005). 


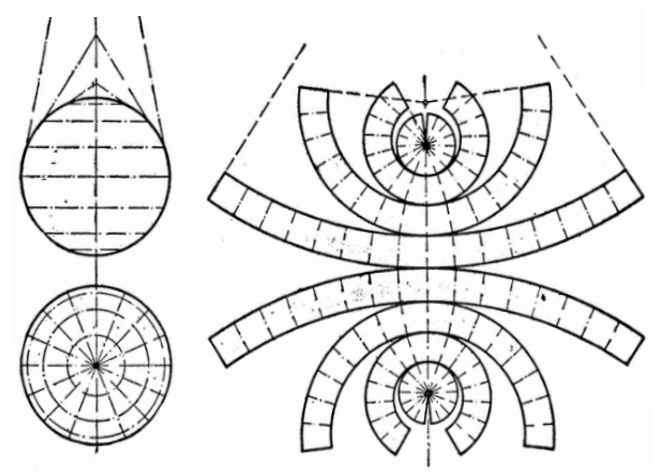

Figure 8. Construction by the Polyconic/Zone method (French, 1911).

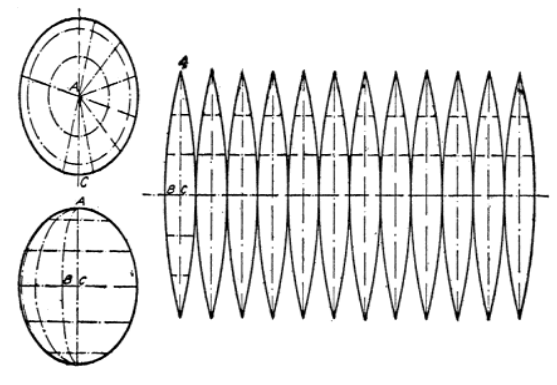

Figure 9. Construction by the Polycylindric/Gore method (French, 1911)

The mass of inflatable structure is measured either by a sensitive weight balance or can be theoretically found by

Mass of the inflatable structure $(m)=4 \pi r^{2}$ t $\rho$

where $r$ is the radius of the envelope, $t$ is the thickness of inflatable envelope material and $\rho$ is the density of the material. This should be multiplied by a factor $\mathrm{K}$ to account for the extra weight of seams, valves, patches, and any other extra components.

Table 2

Different environmental/gas holding layer polymeric materials (French, 1911).

\begin{tabular}{lccccc}
\hline \multicolumn{1}{c}{$[1]$ Material } & Permeability & Weatherability & Flex Fatigue & Achesion to FabricFilm & Heat Sealability \\
\hline PVF(Tedlar (2) & Good & Excellent & Good & Poor & No \\
PTFE(Teflon (8) & Good & Excellent & Good & Poor & Yes $\left(5500{ }^{\circ}\right.$ F $)$ \\
Polyurethane & Fair & Good & Excellent & Excellent & Yes \\
Silicone Rubber & Poor & Excellent & Excellent & Poor & No \\
PVC & Fair & Good & Good & Excellent & Yes \\
Low-Density Polyethylene & Fair & Fair & Excellent & Poor & Yes \\
PVDC (Saran (1) & Excellent & Poor & Fair & Fair & Yes \\
Nylon & Excellent & Poor & Excellent & Fair & Yes \\
Polyester (Mylar (1) & Good & Fair & Fair & Fair & No \\
\hline
\end{tabular}

Mainly four factors affect the selection of material for the inflatable structure; such as cost, durability, ability to sustain the stresses generated during flight conditions, and permeation of lifting gas. The ideal material for the inflatable structure should have a high strength to weight ratio, resistance to environmental degradation, high tear resistance, and low permeability to lighter than air gases (Khoury \& Gillett, 2004; Miller, 2005) A number of material options exist for the construction of the envelope. Polyurethane and biaxialoriented polyethylene terephthalate (BOPET) are commonly used material for 
inflatable structure. Metallised BOPET, also known by the trade name Mylar, is inexpensive compared to polyurethane. However, it is prone to helium leakage at the seams (Nordestgaard, 2007). The punctured holes in Mylar will propagate rapidly compared to polyurethane (Boon, 2004). Table 2 summarizes different environmental/gas holding layer polymeric materials.

\section{Stress analysis on the inflatable structure.}

The inflatable structure of the system can be treated as a pressure vessel. Of all the stresses in three directions developed due to the lifting gas on the material, the most concern is the stress in the hoop direction (Callwood, 2014). If the stress due to a particular pressure of the lifting gas exceeds the material's strength, the envelope structure will burst. It is important to make sure that for all planned flight conditions, the envelope stress remains at or below the appropriate limit. The internal pressure of envelope structure is assumed to be at the bottom. The internal pressure at envelope equator (Figures 10 and 11; Kumar et al., 2016) may be written as

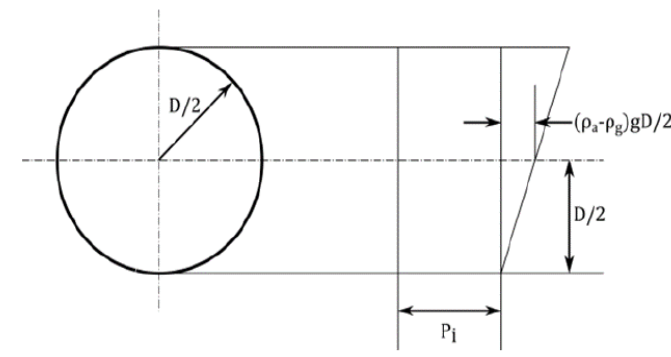

Figure 10. Internal pressure distribution on maximum diameter of spherical envelope (Kumar et al., 2016).

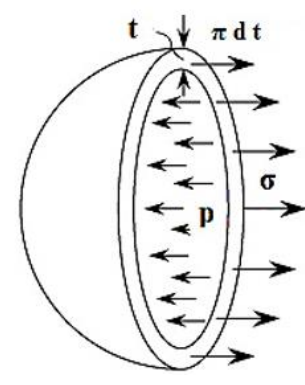

Figure 11. Hoop stress estimation of sphere pressure vessel (Kumar et al., 2016).

$$
P e q=P i+\left(\rho_{a}-\rho_{g}\right) g D / 2
$$

Since the vessel is under static equilibrium, Newton's law can be applied. where $r$ is the radius of the sphere, $t$ is the thickness of envelope, $\sigma$ is the hoops stress,

$$
\begin{aligned}
& 2 \pi r t \sigma=P_{e q} \pi r^{2} \\
& \sigma=\frac{P_{e q} r}{2 t}
\end{aligned}
$$

\section{Maximum Attainable Altitude}

Assuming the inflatable structure can withstand an expansion of $\mathrm{X} \%$ of the total volume $(\mathrm{V})$.

$$
V=\frac{4}{3} \pi r^{3} \quad V^{\prime}=\left(1+\frac{X}{100}\right) * V
$$


To avoid unnecessary stress on the envelope material, the airship should not exceed the altitude where the volume of the airship has increased to V'. Using the equation

$$
\begin{aligned}
& \text { Lifting force }\left(L_{f}\right)=V\left(\rho_{\text {air }}-\rho_{\text {gas }}\right) \\
& \rho_{\text {air }}-\rho_{\text {gas }}=\frac{\text { Lifting force }\left(L_{f}\right)}{V^{\prime}}
\end{aligned}
$$

Figure 6 can then be utilized to determine the maximum altitude achievable without overstressing the envelope material. The radio transmission range also affects the maximum altitude. Different countries have different aviation laws and regulations regarding operation of drones.

According to Federal Aviation Administration (FAA), a smallunmanned aircraft means an unmanned aircraft weighing less than 55 pounds on take-off, including everything that is on board or otherwise attached to the aircraft. But for a lighter than air vehicles positive buoyancy isn't considered while determining the total weight, i.e.; the weight of the vehicle before filling in helium is considered as take-off weight (FAA, 2018).

\section{Selection on Electrical and Electronic Components}

Thrust to weight ratio is defined as thrust needed for unit weight of the system. Racing multirotor vehicles go for higher thrust to weight ratio. Vehicles designed for aerial photography normally select the ratio between 3:1 and 4:1 (Oscar, 2018). There are actually three classes of motors that can be employed in these vehicles. They are brushed motors, brushless out-runner and brushless in-runner motors. For a brushless out-runner motor, the outer shell with magnets rotate freely around a fixed stator. These motors are perfect for a direct drive propeller setup (Imam \& Bicker, 2014). In brushless in-runners the magnetic rotor is inside the stator. Due to friction, brushed motors are inherently less efficient and provide less torque than brushless out-runners. The actual thrust needed to be was calculated by multiplying the weight of the vehicle with the ratio.
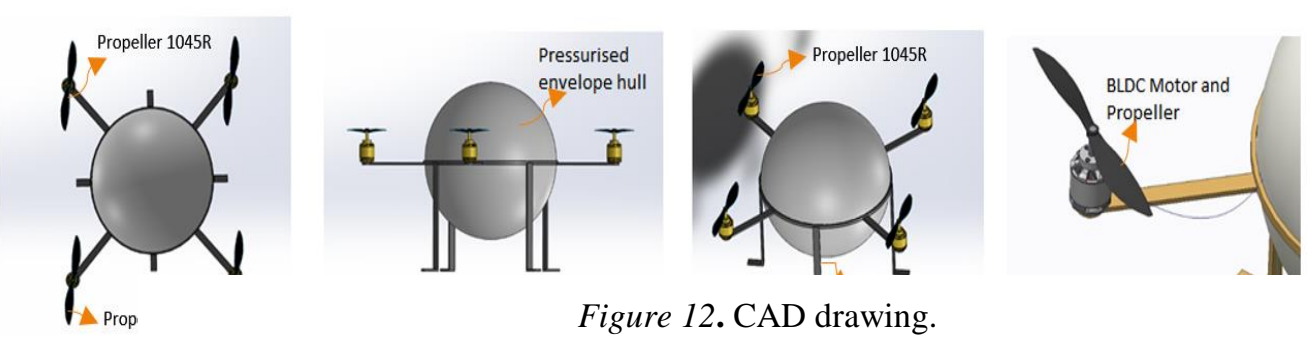

Figure 12. CAD drawing.

Based on the multirotor configuration and number of motors, the thrust required from a single motor was identified. The selection of motors was done by utilizing the thrust table provided by the motor companies. Static and 
dynamic thrust calculators for propellers available online (Staples, 2014) is helpful when thrust charts is not available. The thrust value of motor can also be identified by doing a thrust test (Rahnamai, 2016). An electronic speed control or ESC is an electronic circuit that varies the speed and direction of an electric motor, and can act a dynamic brake (Iman \& Bicker, 2014). There are two current ratings for an ESC; continuous and burst. Continuous current rating indicates the maximum amount of continuous current an ESC can handle safely. Burst current rating indicate the maximum current that the ESC can withstand for short periods of time like 12 seconds. Burst current will be higher than continuous current. For safety, ESC's maximum current rating should be 10$20 \%$ more than the maximum ampere rating of the motor. The four types of commonly used rechargeable batteries in robotics applications are Lithium Ion (Li-ion), nickel-metal hydride (Ni-Mh), nickel-cadmium (Ni-Cd) and lithium polymer (Li-Po). Compared with the other three types, a Li-Po battery has a far superior performance in terms of energy density, charge/discharge efficiency, self-discharge rate, usage durability, and cycle durability Iman \& Bicker, 2014).

Max.continuous current drawn by motor during hover $=$ (No of motors)(Max current drawn by a motors at-100\% throttle) (20)

\section{Max.current drawn \\ = Max continuous current drawn by motor during hover \\ + Tolerance}

Tolerance of $1 \mathrm{~A}$ or $2 \mathrm{~A}$ is provided for accommodating current drawn for other electronics like camera, flight controller etc. Using the above value of maximum current draw and equating it in the equation 22 , the specification of the battery can be fixed.

\section{Maximum current drawn =Battery capacity $($ Ah) $x$ Discharge rate $(C)$}

Flight Controller (FC) is the brain of the vehicle. It has basic sensors like gyroscopes and accelerometer, sensors like barometer, and magnetometer are also available for some FC. It acts as a hub for other peripherals, such as GPS, LED, a sonar sensor, alarm beeper, etc. There is a substantially large collection of microcontroller boards on the market. Custom flight controllers can also be designed.

\section{Computer-Aided Design and Fabrication}

The 3D CAD model of the vehicle is shown in Figure 12. The diameter of the balloon was fixed as 16 inches $(0.4064 \mathrm{~m})$ after the search for standard balloons from the market. $0.2812 \mathrm{~m} 3$ of lifting gas is needed to fill the balloon. The mass of the envelope was found by weighing the balloon after removal of air. The balloon weighed $0.015 \mathrm{~kg}$. Using the lift equation, it was estimated that 
the balloon could lift a weight of $0.3711 \mathrm{~kg}$ at standard conditions. This design will not yield a neutrally buoyant vehicle as the components weight exceed $0.37113 \mathrm{~kg}$. This design was developed more over from the inspiration of a quadcopter design and utilizing the procedure shown in Figure 4. As diameter is known, the frame was made for the same diameter. The material used for the construction of the frame was steel and sheet metal. The base and the ring of the frame were made of the steel and the support base for electronics was made of sheet metal. The design could have been 3D printed. This could have tremendously decreased the weight of the drone and could have increased the performance. A thrust to weight ratio of 3:1 was selected, so a total of thrust produced was $4.5 \mathrm{~kg}$. Each motor provided $1.125 \mathrm{~kg}$ of thrust each. To confirm whether structural steel will be able to take up the thrust provided by the propellers a static structural analysis of the frame was done using Ansys17. The maximum deformation on the arm was $0.0018414 \mathrm{~m}$ which is very small (Figure 13). The equivalent stress is maximum near the attachment of the arm to the ring of the frame (Figure 14). The analysis shows that this arrangement can cause a small amount of dimpling on the envelope where the stand is attached to the ring of the frame (Figure 15).The thrust table was unavailable online for the selected motor propeller configuration, but a few websites have provided details about the maximum thrust. Utilizing the motor parameters as input a simulation was done to check whether the propeller can provide $1.2 \mathrm{~kg}$ of thrust using the Fluent software. A moving mesh method (Kutty \& Rajendran, 2017) was used to get the result. An aerofoil of a propeller is shaped so that air flows faster over the top than under the bottom. There is, therefore, a greater pressure below the aerofoil than above it (Figure 16). This difference in pressure produces the lift. The Ansys simulation provided a thrust value of $13.339937 \mathrm{~N}$ at 7200rpm, which is close to the value found on the internet. 


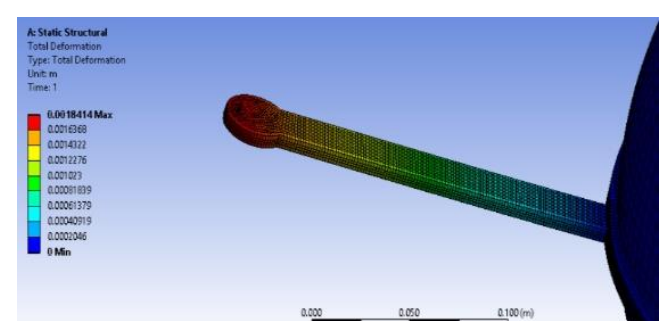

Figure 13. Static structural analysis of the arm (Total deformation).

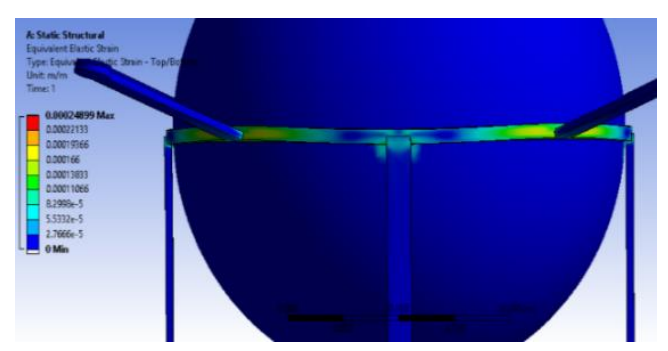

Figure 15. Static structural analysis of the $\mathrm{f}$ (Equivalent strain).

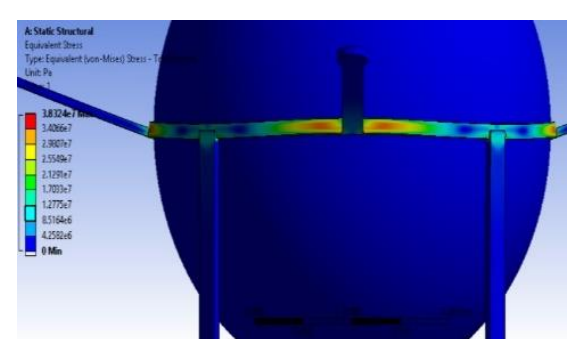

Figure 14. Static structural analysis of the frame (Equivalent stress).

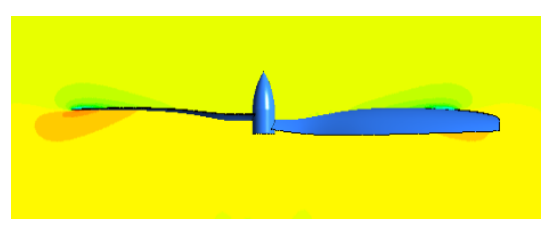

\section{Component specification \& wiring diagram.}

An ESC that can withstand 25A continuous current was selected because the maximum continuous current of the motor is 20A. Four in one ESC would help to reduce the combined weight of components. However separate ESC was used considering the need to replace the whole board for the burnout of one ESC. From the thrust table, the maximum continuous current needed for the motor is $12 \mathrm{~A}$ while using a $3 \mathrm{~S}$ LiPo battery. Adding tolerance, it becomes $13 \mathrm{~A}$. There are 4 motors and the total current was 52A. A 2200mAh 25C LiPo was selected as battery based on the maximum current. There are many flight control boards available in the market. KK 2.1 .5 board was selected as it was relatively cheap as well as had the support of many hobbyists. Wiring of all the electrical and electronic components was done as shown in the Figure 17. The fabricated model image is shown in Figure 18. The electronics are placed above the envelope in this model, but it is preferred to be placed below the envelope so that the centre of mass remains low and thus decrease the chances of flipping during take-off and landing, and increase stability. Changing yaw orientation in turning flight may affect the motors on the trailing side, the KK board automatically compensates this, and the allowance provided to the esc and motors helps to keep the system running effectively. 


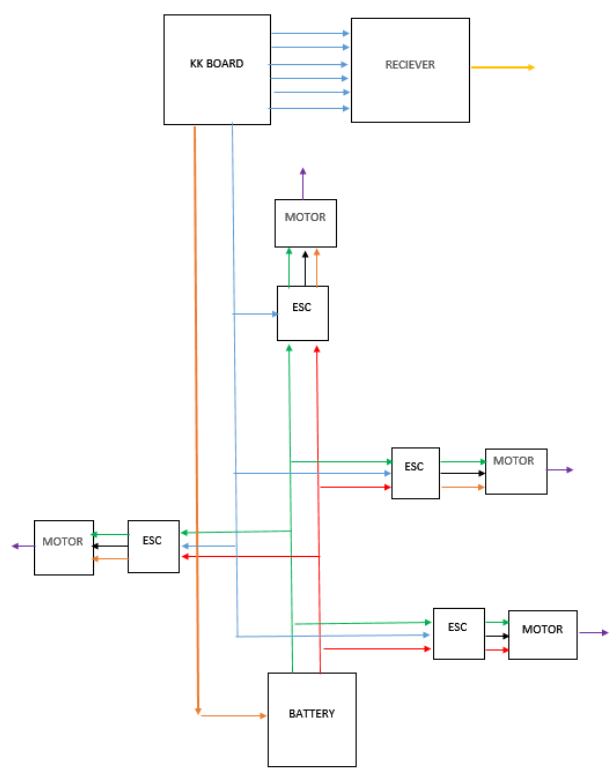

Figure 17. Wiring diagram of all the electrical and electronics components.

\section{Flight testing.}

The rotorcraft vehicle design was put to test flights to see its performance on take-off, transmission, landing, rotation and other movements. For more stabilisation, auto level setting of the KK Board was utilised. The test where conducted on open grounds and the wind was stable. Maximum flight time was 12 minutes on fully charged battery under normal operating conditions. It was found that there was a small probability of flipping of the vehicle during take-off and landing. This is because the batteries and other electronics were placed above the design. It is recommended to keep the centre of mass of the system as low as possible. The configuration achieved six degrees of freedom. Flipping was not possible due to the design structure. However, a more detailed frame design and neutrally buoyant design could help achieve flipping. The frame stood the maximum thrust provided by the motor and no deflection of frame was observed during test flight. Wind tunnel testing can address some of the design issues and will be addressed in the future work.
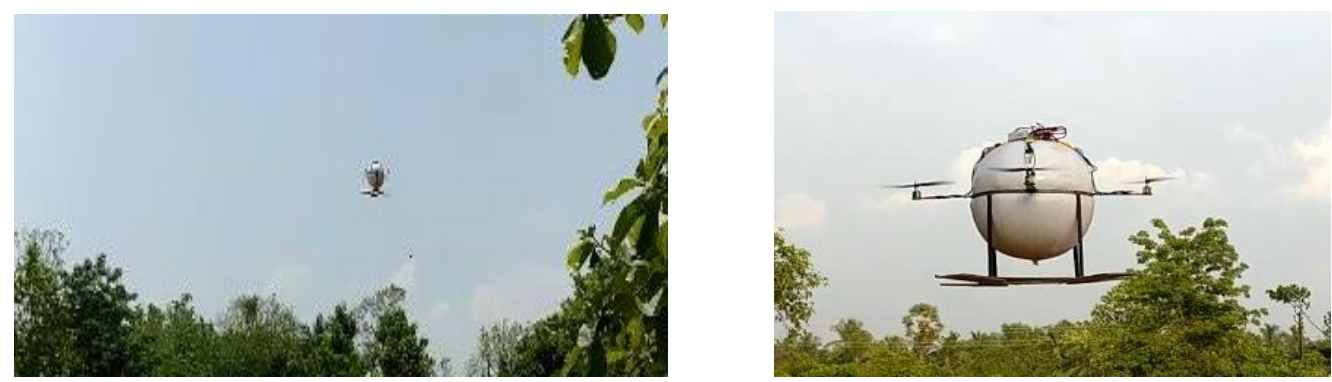

Figure 18. Test flights. 


\section{Conclusion and Future Work}

The design, analysis, and realization aspects of a VTOL vehicle with pressurized structure have been presented. Envelope weight is proportional to surface area and lift is proportional to the volume. Though there is a slight effect on lifting force with altitude and temperature change they are negligible for lower flights ranges. However, for vehicles with high altitude operations, ballonets will have to be incorporated into the design so that the envelope shape is maintained during the ascending and the descent. Buoyancy versus drag is an
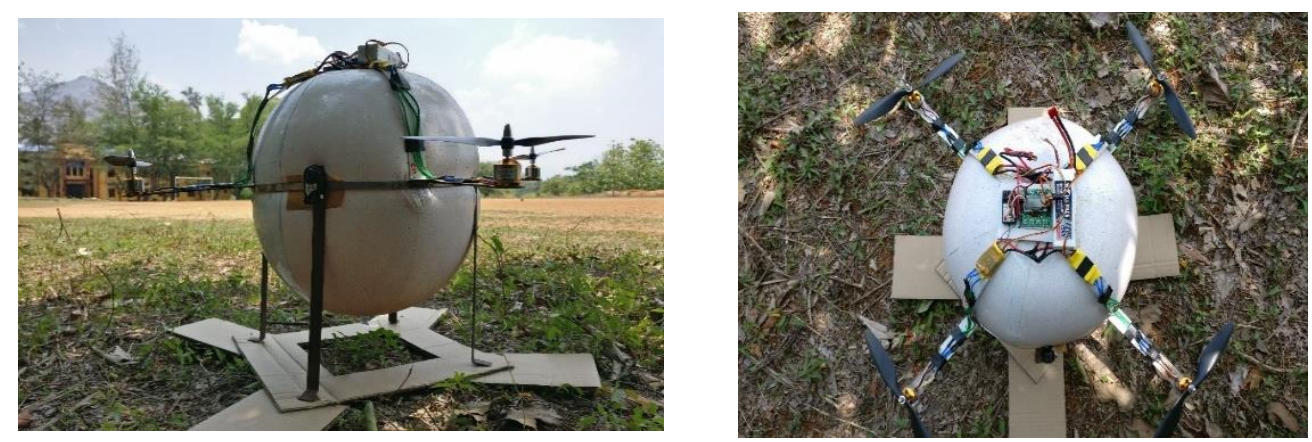

Figure 19. Fabricated model.

important trade-off in designing lighter-than-air vehicles. The stress analysis has then been carried out using both analytical and finite element analysis approach. The model designed using the two developed design procedures has a high potential for improving the efficiency and overcoming the limitations of multirotor vehicles. Neutrally buoyant vehicles can be designed following these procedures. However, it is difficult to design small diameter neutrally buoyant vehicle using design procedure 2 since the component weight will probably exceed the lift force. Flight tests carried out have shown that the vehicle designed is capable of performing the manoeuvres as capable as of normal quadcopters and other multirotor. The efficiency of the current fabricated model can be further increased by 3D printing the frame of the drone, which will reduce the weight of the vehicle tremendously. For vehicles other than neutrally buoyant ones, the centre of mass of the system is made as low as possible to increase the stability and decrease the probability of flipping during take-off and landing. This work holds an excellent prospect for future research and more isolated development in all the applications this particular system can be employed. Further investigations are needed for checking the effectiveness of different motor layout configurations, stabilization and attitude control, motion planning, collision avoidance and fully autonomous operation for intended applications. 


\section{References}

Atherton, K. D. (2017, September 19). Popular science. Retreived from https://www.popsci.com/plimp-plane-blimp-drone

Berie H. T., \& Burud, I. (2018). Application of unmanned aerial vehicles in earth resources monitoring: Focus on evaluating potentials for forest monitoring in Ethiopia. European Journal of Remote Sensing, 51(1), 326-335.

Boon, N. K. (2004). Mini airship patrol craft. Singapore: National University of Singapore.

Burri, M., Gasser, L., K“"ach, M., Krebs, M., Laube, S., Ledergerber, A., . . . Beardsley, P. (2013). Design and control of a spherical omnidirectional blimp. In 2013 IEEE/RSJ International Conference on Intelligent Robots and Systems (IROS), Tokyo, Japan, 2013.

Callwood, K. N. (2014). Preliminary design and evaluation of a tethered balloon system with a constant volume torus envelope for low altitude operations in light winds. Knoxville, TN: University of Tennessee.

Cetinsoy, E., Dikyar, S., Hancer, C., Oner, K., Sirimoglu, E., Unel, M. \& Aksit, M. (2012). Design and construction of a novel quad tilt-wing uav. Mechatronics, 22(6), 723-745.

Choi, K., Cheon, J. W., Kim, H. Y., \& Lee, I. (2016). An automatic uav mapping system for supporting UN (United Nations) field operations. International Archives of the Photogrammetry, Remote Sensing \& Spatial Information Sciences, 41(B4), 85-90.

Duan, G.-T., \& Zhang, P.-F. (2014). Research on application of uav for maritime supervision. Journal of Shipping and Ocean Engineering, 4, 322-326.

Edge, H. L., Brown, A., \& Collins, J. (2012). Pressurized structures-based unmanned aerial vehicle research. Journal of Intelligent \& Robotic Systems, 65(1-4), 603-620.

Federal Aviation Administration. (2018). Jennings-REJ aviation services legal interpretation. Retreived from https://www.faa.gov/about/ office_org/headquarters_offices/agc/practice_areas/regulations/interpre tations/data/interps/2018/jennings-rej\%20aviation\%20services\%20$\% 20(2018) \% 201$ egal\%20interpretation.pdf

Festo. (n.d.a). Airjelly. Retreived from https://www.festo.com/group/en/cms/ 10244.htm

Festo. (n.d.b). AirPenguins. Retreived from https://www.festo.com/group/en/ cms/10242.htm 
Festo. (n.d.c).Air_Ray. Retreived from https://www.festo.com/group/en/cms/ 10245.htm

Festo. (n.d.d). FreeMotionHandling. Retreived from https://www.festo.com/ group/en/cms/11957.htm

French, T. E. (1911). A manual of engineering drawing for students and draftsmen. New York, NY: McGraw-Hill.

Gawale, A. C. (2002, October). Design, fabrication and flight testing of remotely controlled airship. Proceedings of National Conference on LTA Technologies, Aerial Delivery R\&D Establishment, Agra, India.

Ghazbi, S. N., Aghli, Y., Alimohammadi, M., \& Akbari, A. A. (2016). Quadrotors unmanned aerial vehicles: A review. International Journal on Smart Sensing and Intelligent Systems, 9(1), 309-333. doi:10.21307/ijssis-2017-872

Hackney, C., \& Clayton, A. (2015). Unmanned aerial vehicles (uavs) and their application in geomorphic mapping. London, GB: Geomorphological Techniques.

Hassanalian, M., \& Abdelkefi, A. (2017). Classifications, applications, and design challenges of drones: A review. Progress in Aerospace Sciences, 91, 99-131.

Hassanalian, M., Rice, D., \& Abdelkefi, A. (2018). Evolution of space drones for planetary exploration: A review. Progress in Aerospace Sciences, 97, 61-105.

Hollinger, G. A., Pezzementi, Z. A., Flurie, D., \& Maxwell, B. A. (2005). Design and construction of an indoor robotic blimp for urban search and rescue tasks. Swarthmore, PA: Swathmore College.

Imam, A., \& Bicker, R. (2014). Design and construction of a small-scale rotorcraft uav system. International Journal of Engineering Science and Innovative Technology, 3(1), 96-109.

Juang, M. (2017, May 6). CNBC. Reteived from https://www.cnbc.com/ 2017/05/06/thats-no-balloon-its-a-drone-halo-takes-to-the-skies-aslatest-trend-in-uavs.html

Jurić-Kaćunić, D., Librić, L., \& Car, M. (2016). Application of unmanned aerial vehicles on transport infrastructure network. GRAĐEVINAR, 68(4), 287-300.

Khoury, G. A. \& Gillett, J. D. (Eds). (2004). Airship technology. Cambridge, England: Cambridge University.

Kim, S. J., \& Lim, G. J. (2018). Drone-aided border surveillance with an electrification line battery charging System. Journal of Intelligent \& Robotic Systems, 1-14. 
Kim, S. J., Jeong, Y., Park, S., Ryu, K., \& and Oh, G. (2017). A survey of drone use for entertainment and avr (augmented and virtual reality). Augmented Reality and Virtual Reality, 339-352. https://doi.org/10.1007/978-3-319-64027-3_23

Kumar, A., Sati, S., \& Ghosh, A. (2016). Design, testing, and realisation of a medium size aerostat envelope. Defence Science Journal, 66(2), 93-99.

Kutty, H. A., \& Rajendran, P. (2017). 3D CFD simulation and experimental validation of small apc slow flyer propeller blade. Aerospace, 4(1), 10.

Lisso, G. K. (2017, Jamuary 3). Delivery of packages by unmanned aerial vehicles. United States Patent US9536216B1. Retreived from https://patents.google.com/patent/US9536216B1/en

Markets and Markets. (2018). Unmanned aerial vehicle (UAV) market by application (isr, precision agriculture, product deliver), class (tacitcal, male, hal;e, ucav), system (avionics, sensors, payload), mtow ( $<25 \mathrm{~kg}$, $25-150 \mathrm{~kg},>150 \mathrm{~kg}$ ), range, type, and region - global forecast to 2025. Retreived from https://www.marketsandmarkets.com/MarketReports/unmanned-aerial-vehicles-uav-market-662.html

Matsumoto, H., Ichimura, S., Itobe, T., \& Takita, M. (2014, February 2). Aircraft. US Patent US 2017/0029097. Retreived from https://www.uspto.gov/sites/default/files/documents/fy18pbr.pdf

Miller, J. (2005). The design of robust helium serostats. Montreal,QE: McGill University.

Murfitt, S. L., Allan, B. M., Bellgrove, A., Rattray, A., Young, M. A., \& Ierodiaconou, D. (2017). Applications of unmanned aerial vehicles in intertidal reef monitoring. Scientific Reports, 7(1), 10259. doi:10.1038/s41598-017-10818-9

Nordestgaard, N., Ravenscroft, L., \& Bartel, N. (2007). Design and build a small airship. Adelaide, Astralia:The University of Adelaide.

Ohta, A. (2017). Sky magic: Drone entertainment show. In SIGGRAPH '17 ACM SIGGRAPH 2017 Emerging Technologies, Los Angeles, CA.

Ondráček, J., Vaněk, O., \& Pěchouček, M. (2014). Monitoring oil pipeline infrastructures with multiple unmanned aerial vehicles. In Advances in Practical Applications of Heterogeneous Multi-Agent Systems. The PAAMS Collection. PAAMS 2014. Lecture Notes in Computer Science, vol 8473. Springer, Cham. https://doi.org/10.1007/978-3-31907551-8_19

Oscar. (2018). Oscarliang. Retreived from https://oscarliang.com

Papa, U., Pointe, S., \& Core, G. D. (2017). Conceptual design of a small hybrid unmanned aircraft system. Journal of Advanced Transportation, 2017, Article ID 9834247. https://doi.org/10.1155/2017/9834247 
Psirofonia, P., Eliopoulos, P., Samaritakis, V., \& Potamitis, I. (2017). Use of unmanned aerial vehicles for agricultural applications with emphasis on crop protection: Three novel case-studies. International Journal of Agricultural Science and Technology, 5(1), 30-39. doi:10.12783/ijast.2017.0501.03

Puri, V., Nayyar, A., \& Raja, L. (2017). Agriculture drones: A modern breakthrough in precision agriculture. Journal of Statistics and Management Systems, 20(4), 507-518.

Rahnamai, K. (2016). Quadrotor drones thrust measurement apparatus. In Aerospace Conference, 2016 IEEE, Big Sky, MT.

Reinecke, M., \& Prinsloo, T. (2017). The influence of drone monitoring on crop health and harvest size. Paper presented at the First International Conference on Next Generation Computing Applications (NextComp). Mauritius, Republic of Mauritius.

Saeed, A. S., Younes, A. B., Cai, C., \& Cai, G. (2018). A survey of hybrid unmanned aerial vehicles. Progress in Aerospace Sciences, 98, 91-105.

Salvo, G., Caruso, L., \& Scordo, A. (2014). Urban traffic analysis through an uav. Procedia - Social and Behavioral Sciences, 111, 1083-1091.

Sepulveda, E., \& Smith, H. (2017). Technology challenges of stealth unmanned combat aerial vehicles. The Aeronautical Journal, 121(1243), 1261-1295.

Sharf, I., Persson, M. S., St.-Onge, D., \& Reeves,. N. (2013). Development of aerobots for satellite emulation, architecture and art. Experimental Robotics, 88, 167-181. https://doi.org/10.1007/978-3-319-00065-7_13

Simpson, A., Santhanakrishnan, A., Lumpp, J., Cadogan, D., Mackusick, M., \& Scarborough, S. (2004). Flying on air: UAV flight testing with inflatable wing technology. In AIAA 3rd "Unmanned Unlimited" Technical Conference, Workshop and Exhibit, Chicago, IL.

Smith, T., Uhelsky, F., \& Mackusick, M. (2004). Morphing inflatable wing development for compact. In 45th AIAA/ASME/ASCE/AHS/ASC Structures, Structural Dynamics \& Materials Conference, Palm Springs, CA.

Staples, G. (2014, April 13). Electricrcaircraftguy. Retreived from http://goo.gl/yI8voK

Stratistics MRC. (2016). UAV drones - Global market outlook (2016-2022). Retreived from https://www.strategymrc.com/report/drone-servicesmarket 
UK MoD. (2011). Joint doctrine note $2 / 11$ the UK approach to unmanned aircraft systems. Retreived from https://www.law.upenn.edu/live/files/ 3890-uk-ministry-of-defense-joint-doctrine-note-211-the

Van Dosselaer, I. (2014). Buoyant aerobot design and simulation study: $B A D S$. Delft, Netherlands: Delft University of Technology.

Villa, T., Gonzalez, T. F., Miljievic, B., Ristovski, Z., \& Morawska, L. (2016). An overview of small unmanned aerial vehicles for air quality measurements: Present applications and future prospectives. Sensors, 16(7), E1072. doi:10.3390/s16071072.

Wang, Y., Le, S., \& Fan, Z. (2013). A new type of rotor + airbag hybrid unmanned aerial vehicle. International Journal of Energy Science, 3(3), 183-187.

Zhai, H., \& Euler, A. (2005). Material challenges for lighter-than-air systems in high altitude applications. In AIAA 5th Aviation, Technology, Integration, and Operations Conference (ATIO), Arlington, VA.

Zhou, G., Yuan, J., Yen, I.-L., \& Bastani, F. (2016). Robust real-time uav based power line detection and tracking. In 2016 IEEE International Conference on Image Processing (ICIP), Phoenix, AZ. 